\title{
Article
}

\section{Oral Toxicity of Pseudomonas protegens against Muscoid Flies}

\author{
Luca Ruiu *(D) and Maria Elena Mura (D) \\ Dipartimento di Agraria, University of Sassari, 07100 Sassari, Italy; mariaelenamura@uniss.it \\ * Correspondence: lucaruiu@uniss.it
}

\begin{abstract}
The bioinsecticidal action of Pseudomonas protegens has so far been reported against some target insects, and the mode of action remains unclear. In this study, the pathogenicity potential of a recently isolated strain of this bacterial species against fly larvae of medical and veterinary interest was determined. Preliminary experiments were conducted to determine the biocidal action by ingestion against Musca domestica and Lucilia caesar larvae, which highlighted a concentrationdependent effect, with $\mathrm{LC}_{50}$ values of 3.6 and $2.5 \times 10^{8} \mathrm{CFU} / \mathrm{mL}$, respectively. Bacterial septicaemia was observed in the body of insects assuming bacterial cells by ingestion. Such rapid bacterial reproduction in the hemolymph supports a toxin-mediated mechanism of action involving the intestinal barrier overcoming. In order to gain more information on the interaction with the host, the relative time-course expression of selected $P$. protegens genes associated with virulence and pathogenicity, was determined by qPCR at the gut level during the first infection stage. Among target genes, chitinase $D$ was the most expressed, followed by pesticin and the fluorescent insecticidal toxin fitD. According to our observations and to the diversity of metabolites P. protegens produces, the pathogenic interaction this bacterium can establish with different targets appears to be complex and multifactorial.
\end{abstract}

Keywords: entomopathogens; microbial; biological control; insecticidal genes; virulence factors; pest management; mode of action

Key Contribution: A new strain of Pseudomonas protegens is toxic to Musca domestica and Lucilia caesar. Specific bacterial target genes have been associated with entomopathogenicity and septicaemia.

Toxicity of Pseudomonas protegens

against Muscoid Flies. Toxins 2021, 13, 772. https://doi.org/10.3390/ toxins13110772

Received: 30 September 2021

Accepted: 29 October 2021

Published: 1 November 2021

Publisher's Note: MDPI stays neutral with regard to jurisdictional claims in published maps and institutional affiliations.

\section{Introduction}

Pseudomonas protegens is a soil-dwelling bacterium characterized by an increasing scientific and industrial interest as a growth promoting agent for cultivated plants [1]. Like other pseudomonad species, this bacterium is able to colonize the rhizosphere favoring biochemical mechanisms increasing the availability of soil nutrients to the plant. In addition, pseudomonads can act indirectly (plant resistance induction) and directly (i.e., antibiosis) against phytopathogens [2]. The direct action against plant pathogens relies on the production of diverse compounds such as 2,4-diacetylphloroglucinol (DAPG), hydrogen cyanide $(\mathrm{HCN})$, orfamide $\mathrm{A}$, pyoluteorin, pyrrolnitrin, rhizoxin derivatives, toxoflavin, and several enzymes [3]. While some of these metabolites may also have a toxic or inhibitory action against insect pests affecting crops, several Pseudomonas species have developed particular toxins and virulence factors to act more specifically against insects. One of the most studied members of this bacterial genus is $P$. entomophila that acts by ingestion against susceptible targets leveraging a specific toxin secretion system [4]. Similarly, diverse species in the P. fluorescens group may act as insect pathogens [5]. However, those belonging to the sub-clade 1 , including P. protegens, seems to have developed specific gene traits associated with the insecticidal properties [6]. Recent studies have documented an oral infection process implying a fluorescent insecticidal toxin (Fit) complex showing similarity with the makes caterpillars floppy (Mcf) toxin found in the entomopathogenic nematode symbiont Photorhabdus luminescens [7]. However, P. protegens mutants lacking the 
functionality of the gene complex fit were observed to be still active against fruit flies, thus supporting the involvement of other insecticidal compounds [8]. In the light of the few studies available, the mechanism of action of $P$. protegens on susceptible insects still appears to be poorly understood. In order to increase understanding of $P$. protegens target range and entomopathogenic mode of action, we conducted bioassays on different muscoid fly larvae investigating the possible involvement of genes encoding for some putative protein toxins and virulence factors. For this purpose, gene expression profile was studied at the transcriptional level after oral administration of a new strain of the bacterium. Because target genes are in common between different $P$. protegens strains, the output of this study is useful to deepen the knowledge also of other strains of this species.

\section{Results}

Different experiments were designed to investigate the action of $P$. protegens on larvae of two common muscoid fly species, the housefly Musca domestica L. and the blow fly Lucilia caesar L. For this purpose, the recently isolated strain CO1, whose insecticidal properties against a wide range of pests was previously reported [9], was used.

\subsection{Oral Toxicity}

To determine the ability of P. protegens to act in the gut of larvae after ingestion, insects were reared for $72 \mathrm{~h}$ on artificial diets incorporating different concentrations of bacterial cells. As a result, the bacterium was found to have a clear toxic action on both house fly and blow fly larvae, which confirms its ability to interact with gut barriers (i.e., peritrophic matrix, epithelium) and, eventually, cause a septicaemia.

As shown in Figures 1 and 2, toxicity was concentration-dependent and a significant action with $100 \%$ mortality for the highest concentrations assayed, was achieved on both species after rearing larvae for $72 \mathrm{~h}$ in a treated diet (M. domestica: $\mathrm{F}_{3,132}=760.74, p<0.0001$; L. caesar: $\left.\mathrm{F}_{3,132}=493.72, p<0.0001\right)$. Significant increase in mortality was observed in samples exposed for a longer time to each assayed concentration (M. domestica: $\mathrm{F}_{2,132}=258.85$, $p<0.0001 ;$ L. caesar: $\left.\mathrm{F}_{2,132}=251.21, p<0.0001\right)$.

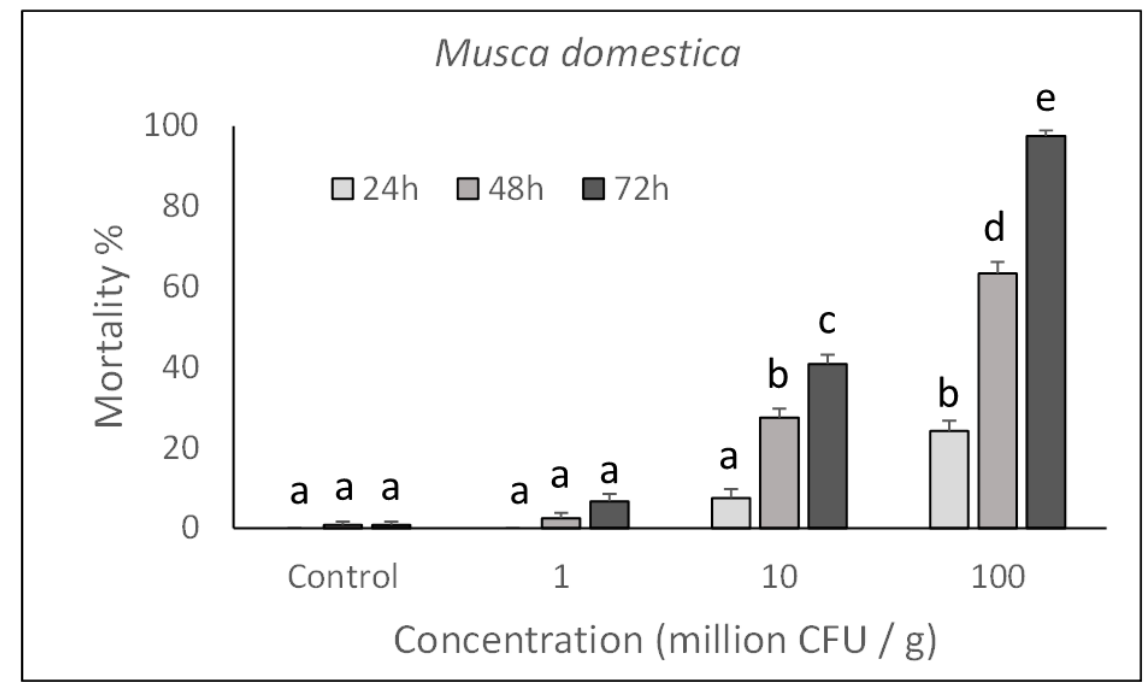

Figure 1. Over time mortality (mean $\pm \mathrm{SE}$ ) of $\mathrm{Musca}$ domestica larvae reared on a diet treated with different $P$. protegens concentrations. Different letters above bars indicate significantly different means (ANOVA Mixed Proc., Tukey adjusted $p<0.05$ ).

Based on the Probit analysis, M. domestica and L. caesar larvae appeared to have a similar susceptibility to $P$. protegens with an $\mathrm{LC}_{50}(\mathrm{CI})$ value of $3.6(2.1-4.9) \times 10^{8} \mathrm{CFU} / \mathrm{mL}$ for $M$. domestica (Slope $=1.872 \pm 0.19 ; \chi^{2}=14.16 ; \mathrm{df}=86$ ) and $2.5(1.1-4.1) \times 10^{8} \mathrm{CFU} / \mathrm{mL}$ for $L$. caesar $\left(\right.$ Slope $\left.=2.804 \pm 0.26 ; \chi^{2}=19.63 ; \mathrm{df}=86\right)$ ). 
A bacterial septicaemia was observed in hemolymph samples collected from dead larvae and observed under a phase microscope.

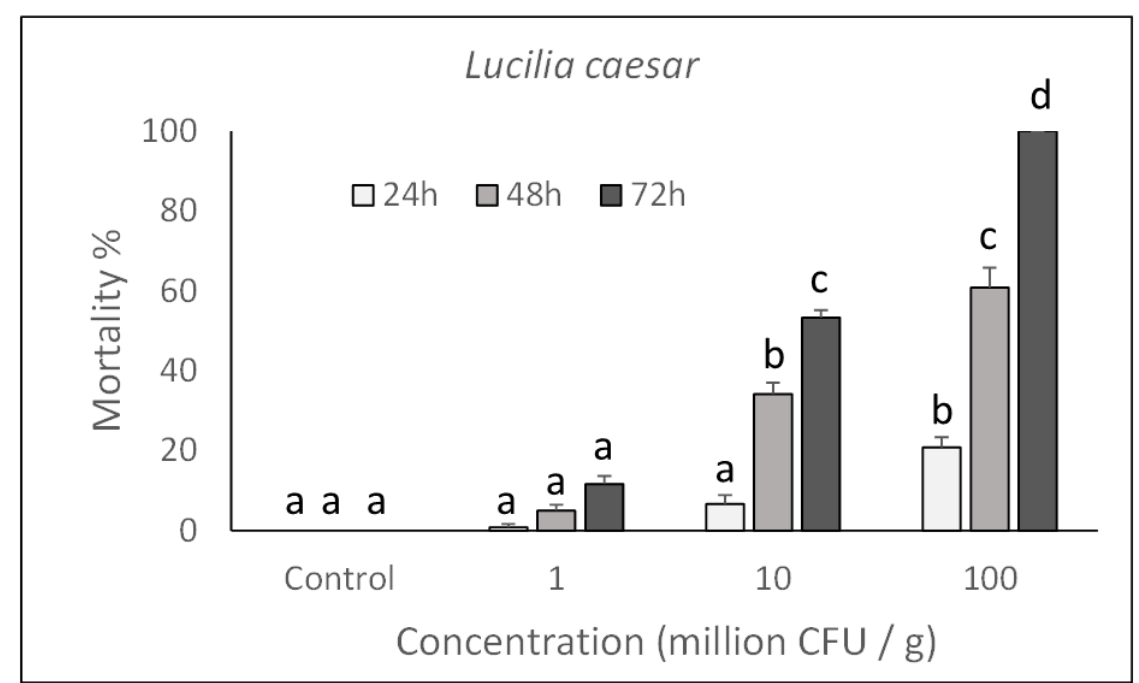

Figure 2. Over time mortality (mean $\pm \mathrm{SE}$ ) of Lucilia caesar larvae reared on a diet treated with different $P$. protegens concentrations. Different letters above bars indicate significantly different means (ANOVA Mixed Proc., Tukey adjusted $p<0.05$ ).

\subsection{Post-Injection Pathogenicity}

The pathogenicity of $P$. protegens strain CO1 was evaluated on $M$. domestica and L. caesar larvae by injecting two doses (high: $1000 \mathrm{CFU} /$ larva; low: 100 CFU/larva) into their body and assessing their mortality during the next $48 \mathrm{~h}$. As shown in Figures 3 and 4 , a significant increase in mortality percentage nearly reaching $100 \%$ in $48 \mathrm{~h}$ for both fly species, was observed in comparison with control larvae injected with PBS. Mortality was significantly affected by the injection dose (M. domestica: $\mathrm{F}_{2,47}=469.65, p<0.0001$; L. caesar: $\left.\mathrm{F}_{2,47}=884.42, p<0.0001\right)$, time after injection $\left(M\right.$. domestica: $\mathrm{F}_{1,47}=98.49, p<0.0001$; L. caesar: $\left.\mathrm{F}_{1,47}=171.00, p<0.0001\right)$ and the interaction between these factors $(M$. domestica: $\mathrm{F}_{2,47}=23.47, p<0.0001 ;$ L. caesar: $\left.\mathrm{F}_{2,47}=65.05, p<0.0001\right)$.

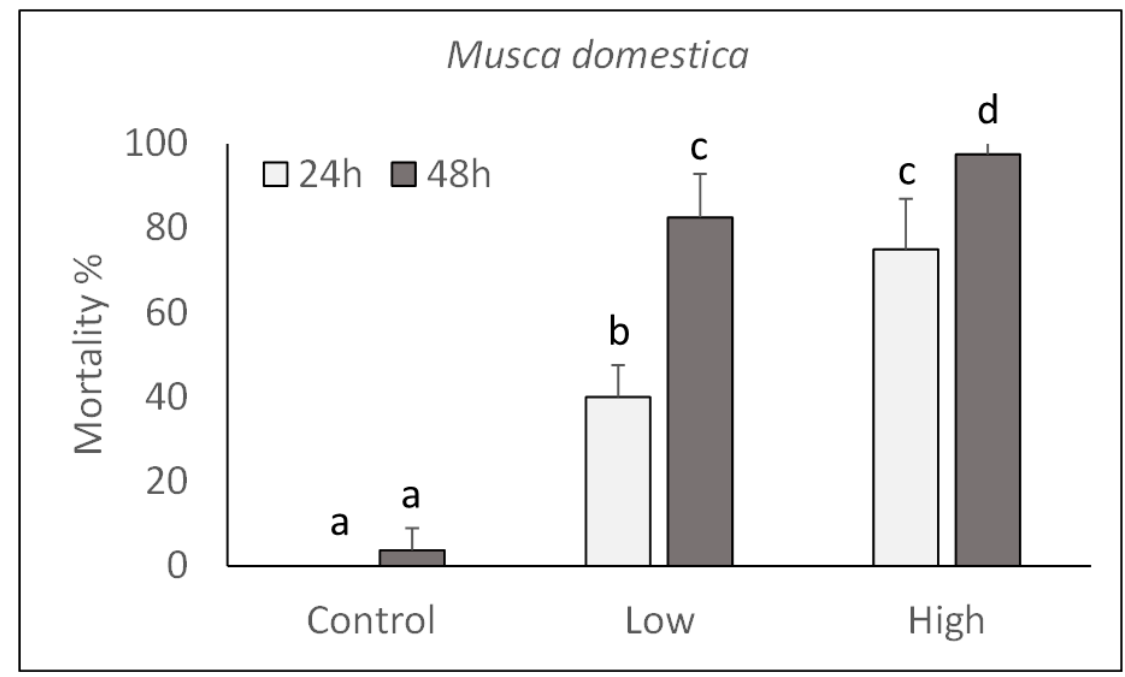

Figure 3. Over time mortality (mean $\pm \mathrm{SE}$ ) of Musca domestica larvae injected with different doses of $P$. protegens (high $=1000 \mathrm{CFU} /$ larva; low $=100 \mathrm{CFU} /$ larva). Different letters above bars indicate significantly different means (ANOVA Mixed Proc., Tukey adjusted $p<0.05$ ). 


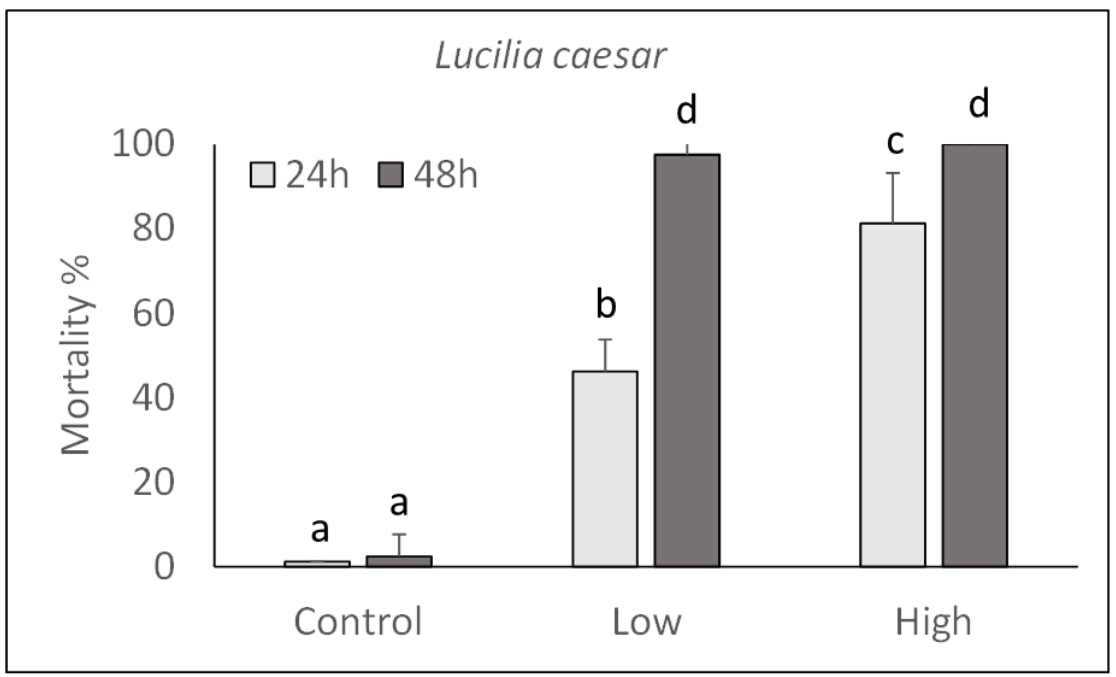

Figure 4. Over time mortality (mean $\pm \mathrm{SE}$ ) of Lucilia caesar larvae injected with different doses of P. protegens (high $=1000 \mathrm{CFU} /$ larva; low $=100 \mathrm{CFU} /$ larva). Different letters above bars indicate significantly different means (ANOVA Mixed Proc., Tukey adjusted $p<0.05$ ).

In order to determine the ability of P. protegens to reproduce in the insect haemocoel, the time-course bacterial growth was determined in hemolymph samples collected from M. domestica larvae injected with $1000 \mathrm{CFU}$. A progressive and rapid increase in bacterial abundance in the larval body was observed at consecutive time intervals after injection, confirming the suitability of insect tissues for bacterial growth. A significant correlation between concentration and time was therefore observed (adjusted $\mathrm{R}^{2}=0.5273, \mathrm{~F}=44.5$, $p<0.0001$ ) (Figure 5).

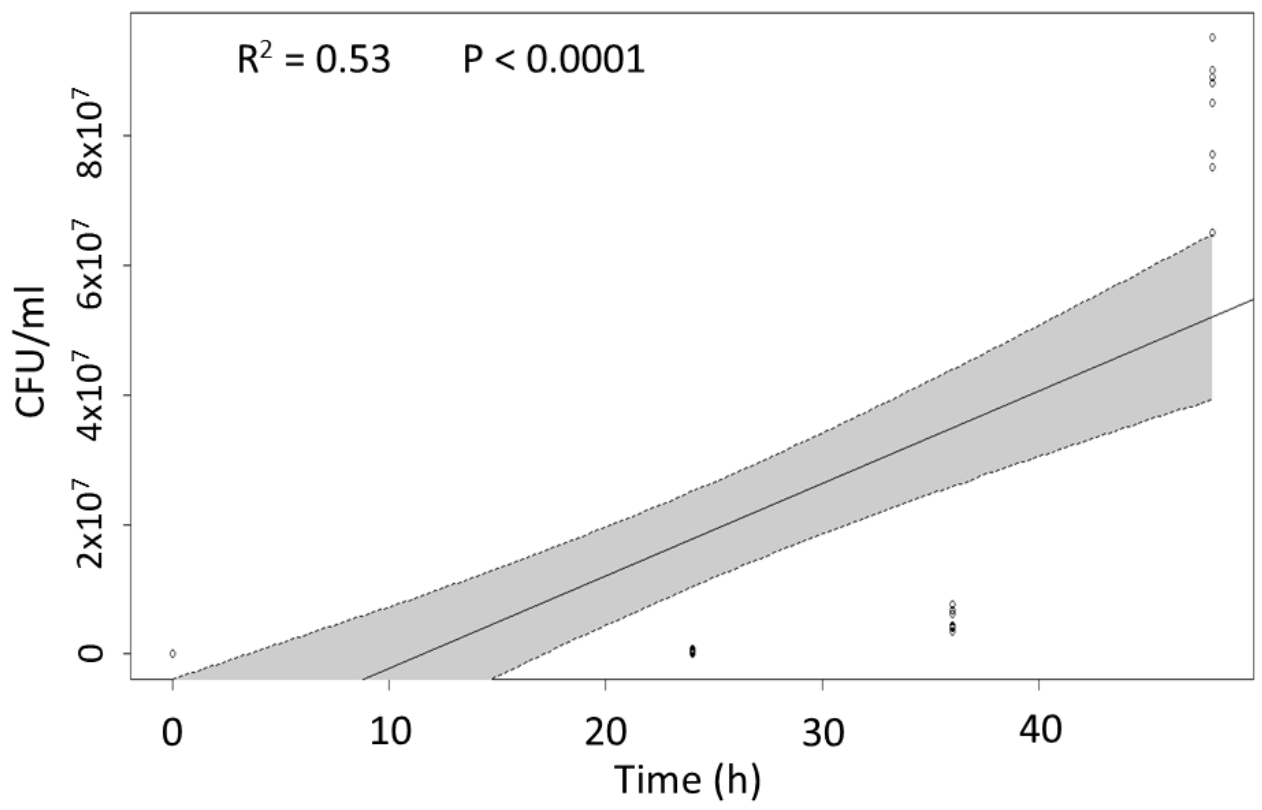

Figure 5. Linear regression plot with $95 \%$ confidence intervals (shaded areas) representing the relationship between $P$. protegens abundance in the insect body (CFU/mL of hemolymph) and time after bacterial inoculation.

\subsection{In Vivo Expression of Bacterial Genes}

Based on the lethal effects observed in ingestion bioassays and on the ability of P. protegens to reproduce in the insect body, gene expression analyses were conducted to gain new knowledge about the mechanism of action enacted by the bacterium during the 
first phase of infection. For this purpose, relative time course expression of P. protegens genes associated with virulence and pathogenicity, was determined at the gut level during the first infection stage. Relative expression of selected target genes (chitinase D, toxin HipA, toxin RelE, pesticin, cytotoxin FitD) at different time intervals (2, 6 and $12 \mathrm{~h})$ after exposing house fly larvae to bacterial cells is shown in Figure 6.

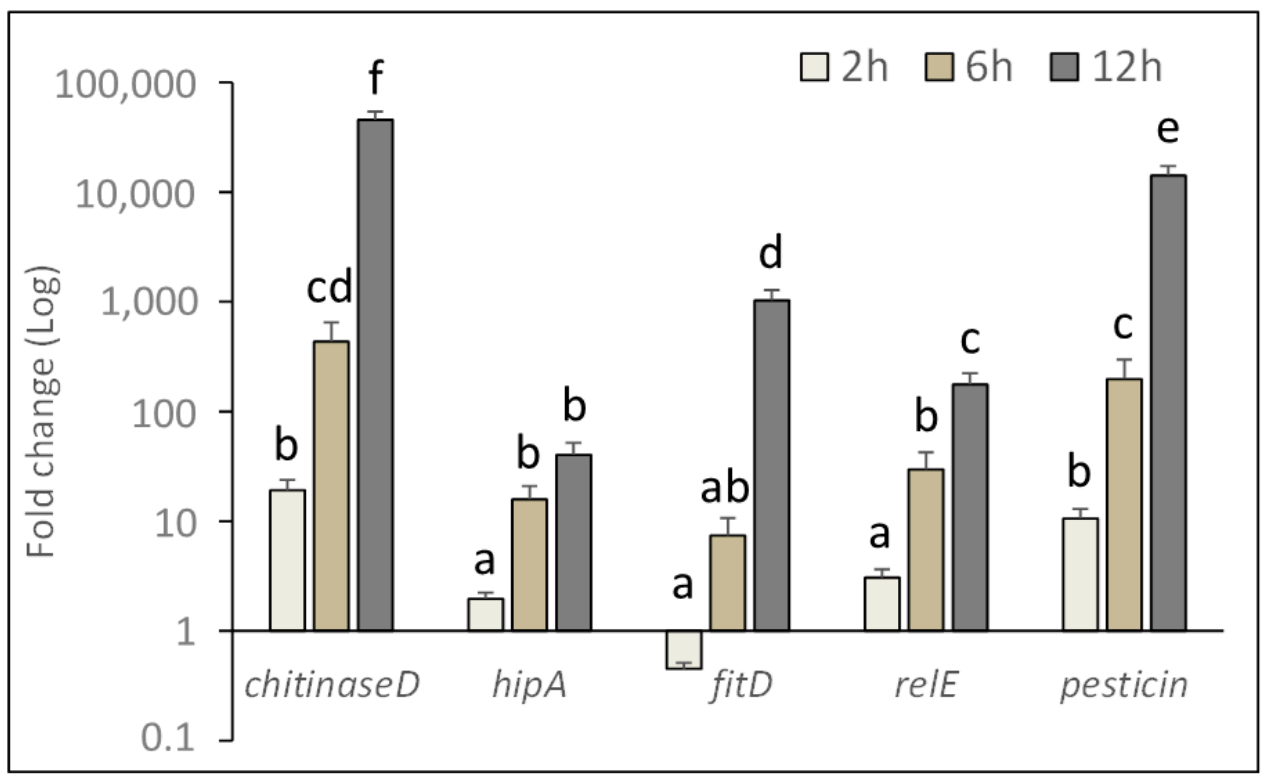

Figure 6. Relative expression of pathogenicity related genes of $P$. protegens at the gut level of treated house fly larvae during the initial infection phase. Fold change was calculated using bacterial $16 S$ $r R N A$ and insect $\beta$-actin transcript abundance for qPCR data normalization. Different letters above bars indicate significantly different means (2-ways ANOVA, Tukey adjusted $p<0.05$ ).

Target gene $\left(\mathrm{F}_{4,134}=23.16, p<0.0001\right)$, time after injecting the bacterial inoculum $\left(\mathrm{F}_{2,134}=43.48, p<0.0001\right)$, and the interaction of these two factors $\left(\mathrm{F}_{8,134}=22.50, p<0.0001\right)$, significantly affected gene expression level in the insect gut.

A significant increase in the relative expression of these genes was observed over time, achieving a maximum at $12 \mathrm{~h}$ after exposure to the bacterium, (chiD: $\mathrm{F}_{3,29}=56.35$, $p<0.0001$; hipA: $\mathrm{F}_{3,29}=22.11, p<0.0001 ;$ fitD: $\mathrm{F}_{3,29}=61.90, p<0.0001$; relE: $\mathrm{F}_{3,29}=38.37$, $p<0.0001$; pesticin: $\left.\mathrm{F}_{3,29}=49.28, p<0.0001\right)$. Among target genes, chitinase $D$ was the most expressed, followed by pesticin and fitD.

\section{Discussion}

The genus Pseudomonas includes several species with insecticidal properties, such as the well-known P. entomophila that acts by ingestion causing damages to the midgut epithelium of susceptible insects, exploiting a specific toxin secretion system [4]. Accordingly, genomic analyses of different pseudomonads have revealed some well-conserved insecticidal traits, in particular associated with the $P$. fluorescens group that, within clade-1, includes P. protegens. Consistently, our study demonstrated that strain CO1 of P. protegens, originally isolated from the hemolymph of diseased G. mellonella larvae [9], is toxic by ingestion to M. domestica and L. caesar larvae. Such results, corroborate previous reports on the per-os insecticidal potential of this bacterial species, supporting the ability of the bacterium to interact at the intestinal level [10]. Lethal effects were concentration-dependent, as normally expected for entomopathogenic bacteria acting by ingestion on these target insects [11]. $\mathrm{LC}_{50}$ values are comparable with those observed on other entomopathogenic bacteria with similar mode of action and effective on muscoid flies [12]. Our experiments conducted injecting bacterial cells in the house fly larvae haemocoel, showed that $P$. protegens reproduces well in the hemolymph, which represents a natural target substrate ultimately 
allowing the bacterium to express its biotic potential. However, when bacterial cells enter the insect body by ingestion, in order to reach the haemocoel, the intestinal barriers, mainly represented by the peritrophic matrix and the epithelium, have first to be overcome.

Similar to other entomopathogenic bacterial species active by ingestion, such as the well-known Bacillus thuringiensis, the pathogenic process is expected to involve insecticidal toxins interacting specifically with the intestinal epithelium. Normally, this interaction involves the binding to epithelial cell receptors and the alteration of cell permeability with a consequent flux of ions and water, leading to the intestinal barrier disruption and allowing the bacterium to reach the hemocoel [13]. According to such scenario, in our ingestion experiments, dead larvae showed a bacterial septicaemia. To achieve this, the bacterium must be equipped with an adequate arsenal of toxins and virulence factors. Consistently, P. protegens was observed to harbor some insecticidal-related genes ([6], like other members of the P. fluorescens group, in which insecticidal toxin complex (Tc) gene homologues typical of the entomopathogenic nematode symbiont Xenorhabdus and Photorhabdus species, are frequently found [14]. In the case of P. protegens, the insecticidal potential has been attributed to the fluorescent insecticidal toxin (Fit), a large protein similar to the Makes caterpillars floppy (Mcf) toxin produced by Photorhabdus luminescens [7]. The fitD gene domain is flanked by a protein secretion system including fit $A B C$ and fit $E$ genes and the regulatory genes fit $G$ and fit $H$. While the expression of fitD gene after bacterial injection or ingestion was shown to be involved in the insecticidal action, significant per os toxicity of $P$. protegens mutants lacking fitD gene was observed in Drosophila melanogaster, which supported a more complex mechanism of action involving other virulence factors, among which orfamide A, chitinases and phospholipases were reported as possible candidates $[6,8]$. Although the implication of some of these compounds in the insecticidal action has been at least partially documented, numerous aspects of the mechanism of action remain unclear.

Our study with house fly larvae investigated the possible role of a selection of genes, well conserved in the genome of P. protegens, in the initial phase of infection, following ingestion of bacterial cells. The overtime increasing over-expression of these genes, supports their involvement in an action against midgut barriers, which would precede haemocoel invasion and septicemia. In addition to FitD that might be directly involved in cytotoxicity toward epithelial cells [15,16], the observed upregulation of chitinase D may significantly help overcoming the first barrier offered by the peritrophic matrix containing chitin. This hypothesis corroborates the mode of action observed in Tc-like protein complexes containing eighter insecticidal toxins and chitinases acting synergistically to break through the intestinal barrier [17]. The engagement of other putative virulence factors such as pesticine, hipA and relE may further increase P. protegens virulence and help counteracting the innate immune response that normally comes into action at the gut level of insects challenged with an entomopathogenic bacterium to which they are susceptible [18]. The same and other virulence factors expressed by P. protegens might later be involved in favoring the successive stages of the pathogenic process within the insect body. A wider overview of the bacterial metabolites involved in pathogenesis against muscoid flies would be provided by a broader transcriptomic analysis involving RNA-seq analyses.

According to our observations and to the discovery of several metabolites P. protegens may produce, the pathogenic interaction this bacterium can establish with different targets appear to be complex and multifactorial [16]. Evidence in our study of the biocidal potential against pests of veterinary importance, provides additional biological information to the previously reported bioinsecticidal action this bacterial species shows against crop pests and its plasticity establishing plant-beneficial interactions [19]. Despite different degrees of virulence are expected to be associated with diverse $P$. protegens strains, the maintenance within the species of an arsenal of toxins and virulence factors, suggests an evolutionary process in which a conserved pathogenic relationship with insects became established. Future studies will clarify the target range and the role of specific bacterial virulence factors in pathogenesis. 


\section{Materials and Methods}

\subsection{Bacterial Strain and Preparations}

Pseudomonas protegens strain CO1 from the collection of the University of Sassari was selected for this study because of its previously determined toxicity against fly larvae [9]. Bacterial cells were cultured for $72 \mathrm{~h}$ in Luria-Bertani (LB) broth at $30{ }^{\circ} \mathrm{C}$ with shaking at $180 \mathrm{rpm}$. After being harvested by centrifugation at 10,000 rpm for $10 \mathrm{~min}$, cells were resuspended in PBS and quantified through serial dilutions on LB agar plates to determine the number of $\mathrm{CFU} / \mathrm{mL}$. Fresh suspensions were adjusted with water or PBS to obtain the concentration needed in each bioassay.

\subsection{Bioassays}

Bioassays were conducted with larvae of Musca domestica L. (Diptera: Muscidae) and Lucilia caesar L. (Diptera: Calliphoridae) from colonies maintained at the insect laboratory of the Dipartimento di Agraria of the University of Sassari (Italy) using the methods of Ruiu et al. [20].

\subsubsection{Ingestion Bioassays}

To assess the per os toxicity of $P$. protegens on target insects, second instar larvae of $M$. domestica or L. caesar were reared on a diet incorporating the bacterial cell suspension (vigorously mixed with a spatula) at a specific concentration or left untreated (control), according to methods described in Ruiu et al. [9]. Larvae were maintained inside a growth chamber at $25^{\circ} \mathrm{C}$ and $60 \%$ R.H, in groups of 10 individuals inside Petri dishes (3.5 diameter) containing an artificial diet $(2 \mathrm{~g})$ made of wheat bran $(34 \%)$, milk powder $(1 \%)$, and water $(65 \%)(\mathrm{wt} / \mathrm{wt})$ for $M$. domestica, and moistened $\operatorname{dog}$ food for $L$. caesar. Each experiment involved 4 replications and was repeated 3 times. Mortality was recorded daily for $72 \mathrm{~h}$. To determine the median lethal concentration, the following concentration range was assayed: $1 \times 10^{9}, 5 \times 10^{8}, 2.5 \times 10^{8}, 1 \times 10^{8}, 5 \times 10^{7}, 2.5 \times 10^{7}, 1 \times 10^{7}, 1 \times 10^{6} \mathrm{CFU} / \mathrm{g}$ of diet.

\subsubsection{Injection Bioassays}

In order to determine the ability of P. protegens to reproduce in insect haemocoel, bacterial cell suspensions were injected by a Hamilton syringe $(2 \mu \mathrm{L} /$ larva) into the ventral intersegmental region of surface sterilized third instar larvae of $M$. domestica and of L. caesar. Each larva received either a higher (1000 CFU / larva) or a lower (100 CFU/larva) dose. Control larvae were instead injected a PBS solution. Infected and control larvae were maintained on filter paper at $25{ }^{\circ} \mathrm{C}$ and $50 \%$ R.H. inside Petri dishes in groups of 10 individuals. Each treatment had four replicates and larvae were inspected every day for $48 \mathrm{~h}$ to assess mortality.

In a different injection experiment according to the same design and involving 3 replicates, pools of 10 larvae were sampled at different time intervals after injection $(12,24,36$, and $48 \mathrm{~h})$ and their hemolymph collected to be analyzed for the abundance of P. protegens. For this purpose, the number of colony forming units (CFU) was determined by serial dilutions and growth on LB plates. This experiment was repeated twice with three technical replicates.

\subsection{Insecticidal Protein Gene Expression at Gut Level}

This experiment was designed to investigate the involvement of bacterial virulence factors in the post-ingestion action at the gut level. For this purpose, a selection of pathogenicity related genes was preliminarily identified in the genome of reference P. protegens strain $\mathrm{CHAO}$, taking into account previous reports on this bacterial species virulence against insects $[15,16,19]$. This included genes encoding for chitinases and insecticidal toxins as listed in Table 1 that shows primer pairs designed on their sequences for qPCR. Expression of these genes was determined at the transcriptional level on pools of $M$. domestica larvae collected at different time intervals $(2,6,12 \mathrm{~h})$ after being reared on the previously described artificial diet incorporating P. protegens at a concentration of $10^{8} \mathrm{CFU} / \mathrm{g}$. Individually dis- 
sected intestines from treated and untreated (control) larvae were pooled $(n=10)$ for total RNA extraction using TRIzol ${ }^{\circledR}$ Reagent (Life Technologies, Carlsbad, CA, USA) following manufacturer's protocol [21]. After being quantified and purity checked by a NanoDrop ND-1000 Spectrophotemeter (Thermo Scientific, Waltham, MA, USA), RNA was treated with RQ1 RNase-Free DNase (Promega) and retrotranscribed to first-strand cDNA with Random Hexamer Primers (Life Technologies), SuperScript ${ }^{\circledR}$ II Reverse Transcriptase (Life Technologies) and RNaseOUT ${ }^{\mathrm{TM}}$ Recombinant Ribonuclease Inhibitor (Life Technologies) in accordance with manufacturers' instructions. Quantitative PCR reactions were run with Power SYBR ${ }^{\circledR}$ Green PCR Master Mix (Life Technologies) on an Applied Biosystems 7900 HT Fast Real-Time PCR System using the following cycle conditions: denaturation at $95^{\circ} \mathrm{C}$ for $10 \mathrm{~min}$, followed by 40 cycles of $95^{\circ} \mathrm{C}$ for $15 \mathrm{~s}$, annealing at $58^{\circ} \mathrm{C}$ for $1 \mathrm{~min}$, and extension at $60^{\circ} \mathrm{C}$ for $1 \mathrm{~min}$. Primer pairs used in qPCR (Table 1) were preliminarily tested by standard curve and dissociation curve analyses [22] and transcripts abundance was determined according to Livak and Schmittgen [23] using $16 r R N A$ as P. protegens internal control gene and $\beta$-actin as $M$. domestica reference gene for PCR normalization [18]. Three biological replicates (10 flies each) were considered for each analysis that involved three technical replicates.

Table 1. Oligonucleotide sequences used for qPCR analyses.

\begin{tabular}{|c|c|c|c|c|}
\hline \multirow{2}{*}{ Toxin Gene } & \multirow{2}{*}{ Abbreviation } & \multirow{2}{*}{ Acc. Number } & \multicolumn{2}{|c|}{ Primer Sequence } \\
\hline & & & Sense $5^{\prime}-3^{\prime}$ & Antisense $5^{\prime}-3^{\prime}$ \\
\hline chitinase D & ChiD & NC_021237.1 & $\begin{array}{c}5^{\prime} \text { CATATCGAATTGCACAAG- } \\
\text { GGCAACGAACAG 3' }\end{array}$ & $\begin{array}{c}\text { 5’ AGGCGCCATGCTGA- }^{\prime} \text { AGATGAAGTGCTT 3' } \\
\text { TGAT }\end{array}$ \\
\hline toxin HipA & HipA & NC_021237.1 & $\begin{array}{c}\text { 5' CTGCGACATGCTC- } \\
\text { AGAAGCGAGTTCCACTA 3' }\end{array}$ & $\begin{array}{l}\text { 5’ ACGCAGGTAGT- } \\
\text { CGGCCACCAGCTC 3’ }\end{array}$ \\
\hline toxin RelE & RelE & NC_021237.1 & $\begin{array}{l}\text { 5' ATGGCGAAGCC- } \\
\text { GGAGAGGAACCCA 3' }\end{array}$ & $\begin{array}{l}\text { 5' AAGGTCACAAG- } \\
\text { ACCGGCTCGGGCC 3' }\end{array}$ \\
\hline pesticin domain protein & Pesticin & NC_021237.1 & $\begin{array}{c}\text { 5' ATGTCACGCTACGC- } \\
\text { GATTGATTTCAGTTTTATC3' }\end{array}$ & $\begin{array}{l}5^{\prime} \text { TGATGTTCAAGGGC- } \\
\text { TGGCCGTCGAGAA 3' }\end{array}$ \\
\hline cytotoxin FitD & FitD & EU400157.2 & $\begin{array}{c}\text { 5' CGCCAACACCGA- } \\
\text { GCCACAGCCGGAGG 3' }\end{array}$ & $\begin{array}{c}5^{\prime} \text { CGCGTTCAGGC- } \\
\text { CGTCCACATGCGCCAC 3' }\end{array}$ \\
\hline $16 s \mathrm{rDNA}$ & $16 S$ rDNA & NR_114749.1 & $\begin{array}{c}5^{\prime} \text { TGGGAGGAAGG- } \\
\text { GCAGTTACCTAATACGTGA } 3^{\prime}\end{array}$ & $\begin{array}{l}5^{\prime} \text { TTCCACCACCСТC- } \\
\text { TACCATACTCTAGC 3' }\end{array}$ \\
\hline$\beta$-Actin & $\beta$-Actin & NW_004765946.1 & $\begin{array}{l}5^{\prime} \text { ATGAGGCTCAG- } \\
\text { AGCAAACGTGGTA 3' }\end{array}$ & $\begin{array}{l}\text { 5' AGTCATCTTC- } \\
\text { TCGCGATTGGCCTT 3' }\end{array}$ \\
\hline
\end{tabular}

\subsection{Statistical Analysis}

Statistical analyses were performed with R software version 3.10 [24] with significance level set at $\alpha=0.05$.

Repeated measures ANOVA (PROC MIXED) with means separation using LSMEANS comparison (adjust $=$ Tukey), was used to analyze overtime mortality data.

The relationship between time and bacterial septicaemia (CFU) in the insect body, was analyzed by linear regression analyses, while median lethal concentrations $\left(\mathrm{LC}_{50}\right)$ were calculated by probit regression.

Two-ways ANOVA, followed by multiple comparison of means (adjust = Tukey) was used to analyzed gene expression fold changes.

Author Contributions: Conceptualization, investigation, data analysis, writing, funding acquisition and project administration, L.R.; methodology and experiments, L.R. and M.E.M. All authors have read and agreed to the published version of the manuscript.

Funding: This research was funded by Fondazione di Sardegna, grant 2017, project "Insect Microbiome Resources" and by Fondo di Ateneo per la ricerca 2020.

Institutional Review Board Statement: Not applicable. 
Informed Consent Statement: Not applicable.

Data Availability Statement: Not applicable.

Conflicts of Interest: The authors declare no conflict of interest.

\section{References}

1. Ruiu, L. Plant-growth-promoting Bacteria (PGPB) against insects and other agricultural pests. Agronomy 2020, 10, 861. [CrossRef]

2. Raaijmakers, J.M.; Paulitz, T.C.; Steinberg, C.; Alabouvette, C.; Moënne-Loccoz, Y. The rhizosphere: A playground and battlefield for soilborne pathogens and beneficial microorganisms. Plant Soil 2009, 321, 341-361. [CrossRef]

3. Philmus, B.; Shaffer, B.T.; Kidarsa, T.A.; Yan, Q.; Raaijmakers, J.M.; Begley, T.P.; Loper, J.E. Investigations into the biosynthesis, regulation, and self-resistance of toxoflavin in Pseudomonas protegens Pf-5. ChemBioChem 2015, 16, 1782-1790. [CrossRef]

4. Vodovar, N.; Vallenet, D.; Cruveiller, S.; Rouy, Z.; Barbe, V.; Acosta, C.; Cattolico, L.; Jubin, C.; Lajus, A.; Segurens, B.; et al. Complete genome sequence of the entomopathogenic and metabolically versatile soil bacterium Pseudomonas entomophila. Nat. Biotechnol. 2006, 24, 673-679. [CrossRef]

5. Ruiu, L. Microbial biopesticides in agroecosystems. Agronomy 2018, 8, 235. [CrossRef]

6. Flury, P.; Aellen, N.; Ruffner, B.; Péchy-Tarr, M.; Fataar, S.; Metla, Z.; Dominguez-Ferreras, A.; Bloemberg, G.; Frey, J.; Goesmann, A.; et al. Insect pathogenicity in plant-beneficial pseudomonads: Phylogenetic distribution and comparative genomics. ISME J. 2016, 10, 2527-2542. [CrossRef] [PubMed]

7. Péchy-Tarr, M.; Bruck, D.J.; Maurhofer, M.; Fischer, E.; Vogne, C.; Henkels, M.D.; Donahue, K.M.; Grunder, J.; Loper, J.E.; Keel, C. Molecular analysis of a novel gene cluster encoding an insect toxin in plant-associated strains of Pseudomonas fluorescens. Environ. Microbiol. 2008, 10, 2368-2386. [CrossRef] [PubMed]

8. $\quad$ Loper, J.E.; Henkels, M.D.; Rangel, L.I.; Olcott, M.H.; Walker, F.L.; Bond, K.L.; Kidarsa, T.A.; Hesse, C.N.; Sneh, B.; Stockwell, V.O.; et al. Rhizoxin analogs, orfamide A and chitinase production contribute to the toxicity of Pseudomonas protegens strain Pf-5 to Drosophila melanogaster. Environ. Microbiol. 2016, 18, 3509-3521. [CrossRef] [PubMed]

9. Ruiu, L.; Virdis, B.; Mura, M.E.; Floris, I.; Satta, A.; Tarasco, E. Oral insecticidal activity of new bacterial isolates against insects in two orders. Biocontrol Sci. Technol. 2017, 27, 886-902. [CrossRef]

10. Ruffner, B.; Péchy-Tarr, M.; Ryffel, F.; Hoegger, P.; Obrist, C.; Rindlisbacher, A.; Keel, C.; Maurhofer, M. Oral insecticidal activity of plant-associated pseudomonads. Environ. Microbiol. 2013, 15, 751-763. [CrossRef]

11. Glare, T.R.; Jurat-Fuentes, J.L.; O'callaghan, M. Basic and applied research: Entomopathogenic bacteria. In Microbial Control of Insect and Mite Pests, 1st ed.; Lacey, L., Ed.; Academic Press: New York, NY, USA, 2017; pp. 47-67.

12. Bedini, S.; Muniz, E.R.; Tani, C.; Conti, B.; Ruiu, L. Insecticidal potential of Brevibacillus laterosporus against dipteran pest species in a wide ecological range. J. Invertebr. Pathol. 2020, 177, 107493. [CrossRef] [PubMed]

13. Adang, M.J.; Crickmore, N.; Jurat-Fuentes, J.L. Diversity of Bacillus thuringiensis crystal toxins and mechanism of action. Adv. Insect Physiol. 2014, 47, 39-87.

14. Waterfield, N.R.; Bowen, D.J.; Fetherston, J.D.; Perry, R.D.; Ffrench-Constant, R.H. The tc genes of Photorhabdus: A growing family. Trends Microbiol. 2001, 9, 185-191. [CrossRef]

15. Rangel, L.I.; Henkels, M.D.; Shaffer, B.T.; Walker, F.L.; Ii, E.W.D.; Stockwell, V.O.; Bruck, D.; Taylor, B.J.; Loper, J.E. Characterization of toxin complex gene clusters and insect toxicity of bacteria representing four subgroups of Pseudomonas fluorescens. PLoS ONE 2016, 11, e0161120. [CrossRef]

16. Keel, C. A look into the toolbox of multi-talents: Insect pathogenicity determinants of plant-beneficial pseudomonads. Environ Microbiol. 2016, 18, 3207-3209. [CrossRef]

17. Landsberg, M.J.; Jones, S.A.; Rothnagel, R.; Busby, J.N.; Marshall, S.D.G.; Simpson, R.M.; Lott, J.S.; Hankamer, M.; Hurst, M.R.H. 3D structure of the Yersinia entomophaga toxin complex and implications for insecticidal activity. Proc. Natl. Acad. Sci. USA 2011, 108, 20544-20549. [CrossRef]

18. Mura, M.E.; Ruiu, L. Brevibacillus laterosporus pathogenesis and local immune response regulation in the house fly midgut. J. Invertebr. Pathol. 2017, 145, 55-61. [CrossRef]

19. Vesga, P.; Flury, P.; Vacheron, J.; Keel, C.; Croll, D.; Maurhofer, M. Transcriptome plasticity underlying plant root colonization and insect invasion by Pseudomonas protegens. ISME J. 2020, 14, 2766-2782. [CrossRef]

20. Ruiu, L.; Satta, A.; Floris, I. Comparative applications of azadirachtin-and Brevibacillus laterosporus-based formulations for house fly management experiments in dairy farms. J. Medical Entomol. 2011, 48, 345-350. [CrossRef]

21. Chomczynski, P.; Sacchi, N. Single-step method of RNA isolation by acid guanidinium thiocyanate-phenol-chloroform extraction. Anal. Biochem. 1987, 162, 156-159. [CrossRef]

22. Pfaffl, M.W. A new mathematical model for relative quantification in real-time RTPCR. Nucleic Acids Res. 2001, 29, e45. [CrossRef] [PubMed]

23. Livak, K.J.; Schmittgen, T.D. Analysis of relative gene expression data using realtime quantitative PCR and the 2(-Delta Delta C(T)) Method. Methods 2001, 25, 402-408. [CrossRef] [PubMed]

24. R Development Core Team. R: A Language and Environment for Statistical Computing; R Foundation for Statistical Computing: Vienna, Austria, 2016. 